\title{
What Makes People Worry about the Welfare State? A Three-Country Experiment
}

\author{
Achim Goerres, \\ Achim.goerres@uni-due.de \\ Professor \\ University of Duisburg-Essen \\ Institute of Political Science \\ Rune Karlsen* \\ rune.karlsen@media.uio.no \\ Associate Professor \\ --University of Oslo, Department of Media and Communication \\ --Research Professor, Institute for Social Research, Oslo \\ Staffan Kumlin \\ staffan.kumlin@stv.uio.no \\ Professor \\ --University of Oslo, Department of Political Science \\ --Institute for Social Research, Oslo
}

\begin{abstract}
Welfare states are exposed to a host of cost-inducing "reform pressures." An experiment implemented in Germany, Norway, and Sweden tests how various reform pressure frames matter for perceptions about the future financial sustainability of the welfare state. Such perceptions have been shown to moderate electoral punishment for welfare reform, but we know little about their origins. Hypotheses are formulated in dialogue with newer research on welfare state change, as well as with older theory expecting more stability in policy and attitudes (i.e. the "new politics" framework). Additionally, we consult research drawing on "deservingness theory." The results suggest large variation in impact across treatments. The most influential path to effective pressure framing is to "zoom in" on specific economic pressure linked to undeserving groups (above all immigration, but also to some extent low employment). Conversely, a message emphasizing pressure linked to a very deserving group (population aging) had little effect. A second conceivable path to pressure framing entails "zooming out," i.e. making messages span a diverse and more broadly threatening set of challenges. This possibility, however, received weaker support.
\end{abstract}

Keywords: Welfare state, Framing, Reform pressure, Welfare state sustainability, Blame avoidance 
This research was carried out under the auspices of the project "Support for the Affluent Welfare State," directed by Staffan Kumlin and funded by the Research Council of Norway (no. 217122). Further funding came from University of Duisburg-Essen to Achim Goerres. We thank our excellent research assistants in these projects: Robin Arens, Hanna Bugge, Hedda Haakestad, Hayfat Hamidou, and Atle Haugsgjerd. Earlier versions were presented at conferences organized by the Council for European Studies (Paris), the European Political Science Association (Edinburgh), the Nordic Political Science Association (Gothenburg), Policy Network (Oxford), in workshops/seminars at Lund University (organized by Moira Nelson) and University of Berne (organized by Isabelle Stadelmann-Steffen), and in various talks in our respective home institutions. A collective round of thanks to the many participants in these events. Finally, we thank the three anonymous reviewers for initiated and helpful comments. 


\section{INTRODUCTION}

Mature welfare states have long been on their way into an austerity phase marked by growing demands and more insecure revenues. A number of "reform pressures" raise costs and increase the needs addressed by existing social protection. Some of the most usual suspects here include ageing populations, unemployment, high dependency-employment ratios, immigration, sovereign debt, and global competition. We investigate what citizens make of such growing reform pressures, if anything. An experiment implemented in Germany, Norway, and Sweden tests if and how citizens react to information about reform pressures and, if so, which particular reform pressure frames matter for beliefs about the future of the welfare state. In formulating hypotheses, we communicate with three bodies of past research. These are relatively distinct but, explicitly or implicitly, they all raise questions about how influential various types of pressure framing might be. Empirically, we shall see that all three literatures contribute to our understanding of the subject matter, at the same time as none of them provides the full story.

The first body of research grows out of Pierson's influential "new politics of the welfare state" framework. ${ }^{1}$ Here, institutional path dependencies together with self-interest and risk-aversion, is assumed to make citizens strongly supportive of the status quo. If true, a reasonable implication is that many are also hostile to the message that the welfare state may not be affordable. Moreover, strong support for the status quo makes political leaders hesitant to publicly debate pressures and implement reforms. Welfare states remain stable despite mounting pressure, at least unless effective "blame avoidance" strategies can be used to obscure political responsibility. One of many such strategies is to publicly argue that pressure is so ubiquitous and overwhelming that we have "no choice" but to reform the welfare state.

\footnotetext{
${ }^{1}$ Pierson 1996, 2001.
} 
A second and more recent body of work analyzes how and why mature welfare states now seem to be changing after all. ${ }^{2}$ Several scholars argue that this is not only due to blame avoidance but also to "credit claiming." Reform-minded politicians argue their case by publicly politicizing growing reform pressures. ${ }^{3}$ Importantly, they mix "cognitive" arguments about economic pressure with "normative" arguments. The focus here is not on massive pressure that supposedly leaves us with "no choice." Rather, serious but ultimately manageable pressures, together with a clear normative cue, are integral to the narratives offered by credit claiming reformers. Meanwhile, citizens do not seem to punish reforming governments at the polls, as implied by the "new politics" framework. True, citizens still support key welfare institutions, but also worry about economic consequences. ${ }^{4}$ Studies in this vein put our dependent variable — welfare state sustainability perceptions — center stage and demonstrate how these perceptions affect preferences and moderate electoral punishment. However, few studies examine how perceptions are formed in the first place. Can they really be regarded as responses to reform pressure, with citizens processing and drawing meaningful conclusions from information about sweeping demographic and economic transformations?

These questions lead to a third accumulation of studies: experimental work on welfare attitudes. Here, and despite surging interest in experiments, ${ }^{5}$ we largely lack studies about reform pressure framing as a broad phenomenon. A large number of studies, however, show the importance of cues about how deserving recipients are. ${ }^{6}$ These studies complement the broader field of welfare state change research by convincingly specifying the "normative"

\footnotetext{
${ }^{2}$ E.g. Hemerijck 2013.

${ }^{3}$ E.g. Levy 2010; Stiller 2010.

${ }^{4}$ e.g. Giger and Nelson 2013.

${ }^{5}$ Druckman et al. 2011.

${ }^{6}$ E.g. Tyler et al. 1997; Slothuus 2007; Petersen et al. 2010.
} 
components of credit claiming narratives. Having said this, deservingness studies typically leave the question of economic sustainability aside. We know little about whether framing of economic pressures can matter in the absence of deservingness cues and — crucially—how the two operate in combination: are citizens more susceptible to economic pressure if provided with the right deservingness cue? We address these issues in an experiment that compares the impact of messages about different types of economic pressures, some of which are linked to (un)deserving groups, whereas some are not linked to any groups.

Our results suggest that reform pressure framing is not universally consequential. Several treatments yield none or weak effects. As far as it goes, this fits with the "new politics" depiction of welfare institutions and citizens as change-resistant despite reform pressure. At the same time, certain treatments were indeed important. This fits with recent work on welfare state change, for example by showing that citizens are in principle perfectly capable of processing and reacting to information about pressures. Moreover, such effects indeed depend on normative cues implicit in pressure frames: the framing strategy most clearly supported by our data is to zoom in on pressures linked to groups seen as undeserving. This is evidenced in particular by immigration-related treatments, but also by treatments related to low employment, and by the fact that a population ageing message had no impact. This hierarchy of effects fits well with deservingness theory. The other possible framing strategy is to zoom out, making messages span a more diverse and broadly threatening set of challenges. This strategy, which is more in line with the "new politics" emphasis on blame avoidance, received some but clearly weaker support.

In addition to effect variation across messages, the results will also reveal intricate patterns of country variation. The final section uses these for an inductive discussion about context-message interactions. This analysis is inductive as our one-shot experiment in "only" three countries cannot (and was not designed to) test contextual hypotheses. It is inductive 
also because results did not corroborate initial expectations. We initially expected pressure framing to be especially influential in contexts marked by more real and perceived unsustainability. In this regard, all three countries are among the more economically stable and sustainable European welfare states, at the same time as there is variation among them. Norway, with its exceptional oil revenues and funds, stands out economically and displays more policy stability (with exceptions for example in pension and family policy). ${ }^{7}$ Hence, we initially reasoned that pressure framing would be less consequential in Norway compared to Sweden and Germany. But results revealed a much more complicated — and in some key respects - the opposite cross-country pattern. This begs new explanations and we identify two broad lessons to be tested in future research. One lesson concerns the importance of immigration. We draw on recent work on the immigration-welfare nexus in opinion formation, raising the possibility that immigration frames not only matter, but perhaps particularly so in Scandinavia. The second lesson is that effects seem to grow in places and policy areas where specific pressures have been recently and massively salient in the public sphere. We illustrate by juxtaposing key findings with key developments in each country. The salience explanation has an interesting implication: pressure framing can "pave the way for its own success," by contributing to a context in which future messages of the same type work better, at least for a period of time.

\section{THE "NEW POLITICS" FRAMEWORK AND WELFARE STATE CHANGE}

Paul Pierson's work on "the new politics of the welfare state" framework is the natural starting point. ${ }^{8}$ This influential framework contains assumptions that imply welfare state stability also in the face of considerable reform pressures. Importantly, the institutions of

\footnotetext{
${ }^{7}$ Bay et al. 2010.

${ }^{8}$ Pierson 1996; 2001.
} 
mature welfare states are thought to generate their own support. This is partly due to large, self-interested and "risk-averse" constituencies defending their benefits. However, broader mechanisms of institutional inertia are invoked to explain why also non-beneficiaries see the status quo as more rational, natural, and even desirable.

Several implications seem to follow. For example, fear of electoral punishment will make office-seeking actors think twice before they propagate, let alone implement, visible welfare reform. Moreover, if it is true that a risk-averse public strongly supports an institutionalized status quo, then a reasonable implication is that citizens are also predisposed against information suggesting that the welfare state is unsustainable. Now, Pierson's framework does not directly address psychological mechanisms of information processing. But much research in political psychology, for example recent work on "motivated reasoning," shows how strong and stable political "predispositions" serve as information filters that make people more prone to accept messages consistent with their predispositions. Conversely, people resist, or even counter-argue against, messages that challenge predispositions. ${ }^{9}$ Thus, a plausible implication of the "new politics" framework, and its depiction of welfare attitudes, is that pressure framing effects are attenuated by strong welfare state support, and are not very consequential overall.

The "new politics" framework has been amended and partly questioned in recent research on welfare state change. ${ }^{10}$ A key finding is that significant reforms have occurred in the last decade or so. ${ }^{11}$ While radical and quick retrenchment is unusual there is increasing

\footnotetext{
${ }^{9}$ E.g. Zaller (1992); Taber and Lodge (2006)

${ }^{10}$ See Jacobs 2016.

${ }^{11}$ Hemerijck 2013; Beramendi et al. 2015.
} 
focus on cost containment, ${ }^{12}$ together with non-negligible cutbacks. ${ }^{13}$ These processes were accelerated in several countries by "the great recession" and the euro-zone crisis. However, austerity-driven retrenchment is not the only reform trajectory." ${ }^{14}$ Welfare states are also being "recalibrated" with "new" risks receiving more attention resulting in expansive reforms in for example family- and active labour market policy. ${ }^{15}$ Relatedly, scholars see a shift from traditional goals like income security and equality to a "social investment" oriented welfare state that is more focused on human capital, and equality of opportunity rather than of condition. $^{16}$

To explain these changes, scholars have reassessed the strategies that actors employ to make change politically and electorally feasible. Of course, under the "new politics" framework reform is very difficult but occasionally possible through "blame avoidance." Increasingly, however, there is also evidence of more offensive "credit claiming" strategies. From this vantage point even unpopular reform may not be "politically suicidal" — as Pierson (2001:416) puts it — if visibly and publicly legitimized. In an overview, Levy argues that welfare reforms have not only been more frequent than "new politics" implies, but also materialized via a more open and communicative route. ${ }^{17}$ Another overview by Bonoli draws similar conclusions but notes that research on "credit claiming" is less developed than the extensive work on blame avoidance. ${ }^{18}$

\footnotetext{
12 Taylor-Gooby 2001; Palier and Martin 2007.

${ }^{13}$ Korpi and Palme 2003; Scruggs 2008.

${ }^{14}$ van Kersbergen, Vis and Hemerijck 2014.

${ }^{15}$ Ferrera 2008, Bonoli 2005.

${ }^{16}$ Morel, Palier and Palme 2012.

${ }^{17}$ Levy 2010, 561.

${ }^{18}$ Bonoli 2012, e.g. Hood 2007; Lindbom 2007; Vis 2016; Wenzelburger and Hörisch 2016.
} 
A small but growing group of studies, however, does find empirical evidence of active credit claiming strategies. Although scholars rely on somewhat different concepts, including “ideational leadership" or "strategic reframing", they demonstrate a number of reoccurring features. ${ }^{19}$ One is pro-active agenda-setting of reform pressures. This goes beyond blame avoidance (where problems are kept off the agenda, unless somebody else can be blamed, or where an economic crisis or otherwise massive pressure can be used as a blame avoidance device). Instead, actors put a reform pressure firmly on the agenda explaining how it makes the search for alternatives sensible. Among other things, this allows politicians to make a positive point out of exercising daring leadership and accusing opponents of sweeping problems under the rug. A further feature is legitimization of visible reform using both "cognitive" and "normative" arguments. Cognitive arguments explain the economic logic behind proposed solutions, such as why reform alleviates resource scarcity. Normative arguments link solutions to values of some sort, such as cultural legacies, fairness, or deservingness. ${ }^{20}$ This stance, too, is different from the archetypal blame avoidance storyline that somebody else or, say, a massive economic crisis forces us to do what is all bad. In sum, then, actors are not necessarily afraid to put pressures on the agenda and publicly argue that choosing seemingly unpopular reform is both economically sensible and can have a normative payoff. This implies a wider applicability of reform pressure framing in political communication than suggested by the new politics framework.

How do citizens fit into this picture of accelerating welfare state change and public argumentation? One set of findings suggest that reforming and retrenching governments are rarely punished at the polls. ${ }^{21}$ This may seem puzzling given the oft-reported high levels of

\footnotetext{
${ }^{19}$ Stiller 2010, Elmelund-Præstekær and Emmenegger 2013.

${ }^{20}$ C.f. Cox 2001; Schmidt 2002.

${ }^{21}$ Kumlin 2007; Armingeon and Giger 2008; Giger 2011; Arndt 2014; Lindbom 2014.
} 
normative welfare support. ${ }^{22}$ However, newer findings show that perceptions of economic unsustainability are typically more negative than, and partly orthogonal to, normative support. ${ }^{23}$ Sustainability perceptions, moreover, appear to have behavioural and attitudinal consequences. Analysing voting behaviour with ESS data, Giger and Nelson show that "the perceived economic strain of social spending tempers generalized support for redistribution and makes many voters relatively more tolerant of a retrenchment agenda." 24 They also suggested to future research that “...fiscal austerity and severe economic conditions together with the demographic challenges might make people more responsive to claims of endangered economic sustainability of the current system of social welfare."

This suspicion has been most thoroughly tested with respect to immigration. Several studies use experimental designs to examine how attitudes react to different types of exposure to immigration. A reoccurring finding and/or interpretation is that effects exist and are not only due to perceived "cultural threat," racism, and the like, but also to the notion that immigration is an economic reason to worry about welfare state sustainability. ${ }^{25}$

Only a handful of experimental ${ }^{26}$ studies have considered the impact of reform pressure beyond immigration. Naumann found that experimental subjects in Germany exposed to detailed quantitative facts about demographic pressures become more accepting of a raised retirement age. ${ }^{27}$ By contrast, Brooks reported that information emphasizing global

\footnotetext{
${ }^{22}$ Svallfors 2012.

${ }^{23}$ E.g. Roosma, Gelissen and van Oorschot 2013

${ }^{24}$ Giger and Nelson 2013, 1091.

${ }^{25}$ e.g. Aalberg et al. 2012; Bay et al. 2016; Hjorth 2016; Cappelen and Midtbø 2016; Fietkau and Hansen 2017; Naumann and Stoetzer 2018; also see Bay and Pedersen 2006.

${ }^{26}$ For non-experimental studies linking pressures with normative welfare support, see Naumann 2014 and Jensen and Naumann 2016.

${ }^{27}$ Naumann 2017.
} 
economic crisis did not sway welfare support in the US. ${ }^{28}$ Kangas, Niemelä, and Varjonen operationalized both "moral sentiments" and "factual viewpoints" on costs of administrative social assistance reform in Finland and found that especially the former built reform acceptance. ${ }^{29}$ These pioneering studies are valuable and we continue down their path. Still, they are limited in two ways. First, most are single-country studies that cannot reveal whether results are highly context-specific or signal a more universal (in)ability to process sustainability problems. Of course, our three-country design is also limited in this regard but offers improvement. A second limitation is more crucial to our endeavor: these studies generally examine only one category of reform pressure (i.e. population aging or immigration). Thus, we know little about whether effects vary across conceivable ways of "framing" the message that the welfare state is pressured.

Framing generally means that certain aspects of reality are highlighted, and others ignored, to promote a problem definition. ${ }^{30}$ Moreover, while framing can generate entirely new beliefs it is likely more effective when it triggers and strengthens considerations already encountered and rehearsed. However, this cannot happen so frequently that it eliminates competing considerations, or crystallizes attitudes completely. Thus, people are seen as ambivalent and malleable, being potentially open to emphasis on competing considerations, ${ }^{31}$ with attitudes varying depending on which ones are accessible in short-term memory. "Framing effects," then, occur when changes in emphasis produce opinion change. ${ }^{32}$ The "reform pressure framing" studied here concerns variation in emphasis on how pressured the

\footnotetext{
${ }^{28}$ Brooks 2011, see also Jerit and Barabas 2006.

${ }^{29}$ Kangas, Niemelä, and Varjonen 2013.

${ }^{30}$ Entman 1993:52.

31 Zaller 1992.

${ }^{32}$ Chong and Druckman 2007, 104.
} 
welfare state is, and what it is pressured by. The next section presents hypotheses about the nature of and conditions for this phenomenon, drawing especially on the "new politics" framework and "deservingness theory." As it turns out, these two frameworks have useful and partly contrasting implications for what the ingredients of successful pressure framing might be.

\section{WHICH TYPES OF REFORM PRESSURE FRAMING MATTER AND AMONG WHOM?}

Past research has demonstrated that citizens from most social and political groups are generally and "sociotropically" concerned with the health of the overall economy. This is seen most clearly in research on economic retrospective and prospective voting, showing that the country's economy matters more than personal pocketbook concerns. ${ }^{33}$ Macroeconomic concerns are also widely seen as the ultimate "valence issue"; while there is disagreement over policy the underlying goal is valued in all social and ideological camps. ${ }^{34}$ Thus, one might reasonably formulate the baseline prediction that references to cost inducing reform pressures generally make citizens worried about welfare state sustainability.

H1: Citizens will be more concerned about welfare state sustainability when exposed to reform pressure framing.

This hypothesis is a useful starting point and it certainly fits with the emphasis on leadership and generally pressure-aware citizens found in recent work on welfare state change. But already at the outset there are reasons to believe things are more complex. We now use the

\footnotetext{
${ }^{33}$ For an overview see Lewis-Beck and Stegmaier 2007.

${ }^{34}$ Stokes 1963.
} 
"new politics" framework and research on "deservingness theory" to develop more curtailed expectations.

\section{Insights from "the new politics" framework}

The "new politics" framework assumes that welfare state institutions have built strong support for status quo. This is partly due to the rise of self-interested constituencies that defend their own benefits and services. Also, the framework relies on institutional theory to explain why status quo often seems both more rational and normatively desirable and also beyond immediate beneficiaries. These assumptions suggest limited room for reform pressure framing, particularly among self-interested and status quo-supporting citizens, but also among the many with more generalized support for social protection and redistribution. Such groups are assumed to punish incumbents for unpopular policy changes prompted by reform pressures. By implication, we expect them to resist messages about pressure and sustainability problems, and formulate two hypotheses:

H2: Generalized welfare state support diminishes reform pressure framing effects.

H3: Support for a specific welfare state policy area diminishes framing effects concerning an associated reform pressure.

It may not show at first sight, but "new politics" assumptions do allow for more effective reform pressure framing of a certain kind. As noted previously, strong vested interests and normative support for status quo make "blame avoidance" strategies necessary for reforming politicians. Work on blame avoidance has conceptualized and examined a long menu of possible strategies. ${ }^{35}$ Many of these are not communicative in nature but rather concern design

\footnotetext{
${ }^{35}$ E.g Hood 2007
} 
of political institutions and public policy. However, some strategies are "presentational" and do concern communication with the public. Of special interest here is the notion that politicians can argue that reform pressure is so massive and ubiquitous that we have "no choice" but to implement necessary changes. Probably the best-documented version of this storyline is that a major economic crisis, with severe unemployment-related budgetary strains, necessitate policies that neither citizens nor decision makers prefer. ${ }^{36}$ But one can also imagine that politicians simultaneously bring up several pressures in a single argument, implying exceedingly strong pressure from multiple angles. In these situations, self-interested and risk-averse citizens may feel it is no longer possible to postpone painful reforms. Put differently, the distinction between immediate self-interest and vague long-term collective interests (not prioritized by citizens under the "new politics" framework) becomes smaller. Additionally, broader references to encompassing pressure make it harder to discern which policy/group will suffer. Overall, we hypothesize:

H4: Reform pressure frames that invoke a larger number of reform pressures, or are otherwise encompassing and broadly threatening, matter more for perceptions of welfare state sustainability.

In sum, then, the "new politics" framework implies limited effectiveness for pressure framing. It is likely to be present and effective mainly in areas with weak initial support or when multiple reform pressures are portrayed as so strong and immediate that obstacles related to self-interest and strong support for status quo are overcome.

\footnotetext{
${ }^{36}$ Kuipers 2006; Starke 2008; Jakobsson and Kumlin 2017.
} 


\section{Insights from "deservingness theory"}

Deservingness theory implies a somewhat different answer to what increases sensitivity to economic messages about reform pressures. Here, the key to stronger effects is to "zoom in" on specific pressures that make citizens think about particular undeserving groups (rather than zooming out on general or multiple pressures). Much past research shows that welfare staterelated attitudes are sensitive to perceived deservingness. Deservingness-oriented reasoning is regarded as a deep-seated, perhaps genetic, tendency that is emotionally based, automated, and chronically salient. It is thought to matter as soon as there is any information about deservingness. ${ }^{37}$ Deservingness theory is related to a broader class of models suggesting that people evaluate the political world in terms of social justice just as much as in terms of personal gain. ${ }^{38}$ To convey the idea, theorists have used terms like "dual utility function", 39 "contingent consent", ${ }^{40}$ or "moral economy". ${ }^{41}$

There are at least two general ways of judging deservingness. The more direct one involves specific deservingness criteria. Van Oorschot distilled five such criteria from a large number of previous studies. ${ }^{42}$ First, people are thought to assess "control over neediness," where those who cannot help their predicament are more deserving. Second, the greater the "level of need", the greater the perceived deservingness. Third, "identity" is thought to matter, i.e., mainly needy people who "belong to us" are deserving. A fourth criterion taps the attitudes of beneficiaries, while a fifth one concerns the "reciprocal relationship" between

\footnotetext{
${ }^{37}$ Slothuus 2007; Petersen et al. 2010; Petersen et al. 2012; Van Oorschot et al. 2017.

${ }^{38}$ Tyler et al. 1997.

${ }^{39}$ Rothstein 1998.

${ }^{40}$ Levi 1997.

${ }^{41}$ Mau 2003.

${ }^{42}$ Van Oorschot 2000.
} 
benefactors and beneficiaries; the solidarity of the former is thought to be contingent on whether the latter adhere to behavioural norms.

Lacking facts needed to apply these criteria citizens can instead use general stereotypes about groups. Van Oorschot finds that Europeans share a common deservingness culture: the old are perceived as the most deserving of public welfare, followed by the sick and disabled, and then the unemployed. ${ }^{43}$ "Immigrants" are more or less universally seen as the least deserving of all. Our experiment draws on this rather universal pecking order. It has implications for reform pressure framing, as some (but not all) reform pressures are implicitly linked to specific groups. This is the case for three of the reform pressures included as treatments in the experiment. Population aging, for example, concerns a group universally regarded as deserving, whereas the opposite is true for immigration. Pressure emanating from high unemployment/low employment concerns groups that are more mixed and where deservingness is evaluated somewhere in between.

Importantly, we extend deservingness assumptions to cover also economic messages about the welfare state. The idea to be tested is that "pressure framing" is more effective if information about costs is mixed with cues about which groups are involved, allowing respondents to see mounting economic pressure through a normative deservingness lens. The suspicion is that deservingness provides the key normative ingredient in broader "credit claiming" narratives that also incorporates "cognitive" arguments about economic pressure. ${ }^{44}$ Two psychological mechanisms may be at play here. First, deservingness-related processing is widely seen as affective and automated and so the evaluation about reform pressures themselves may be shaped by a quick "transfer of affect" preceding, and subsequently shaping, more elaborate thinking about the plausibility of costs. Second, a further mechanism

\footnotetext{
${ }^{43}$ Van Oorschot 2006.

${ }^{44}$ Slothus 2007; Esmark and Schoop 2017
} 
arises from the fact that deservingness criteria themselves are linked to issues of reciprocity, contributions, and even belongingness. Thus, a pressure linked to a less deserving group would seem a more plausible generator of costs, perhaps due to welfare abuse, or lack of taxpaying contributions. We formulate the following general hypothesis:

H5 Reform pressure frames associated with groups perceived as undeserving (i.e. immigration/immigrants) elicit stronger effects than pressure associated with deserving groups (i.e. population ageing/the old).

It is useful to note that $\mathrm{H} 5$ partly overlaps with $\mathrm{H} 3$, which predicts stronger effects with weaker concrete policy support. The overlap arises as policy support correlates with deservingness perceptions of associated groups. A crucial nuance, however, is that the deservingness perspective predicts the strongest impact for very concrete frames that single out specific undeserving groups. "New politics" assumptions imply at least as strong effects when pressures are big and scary (and hence useful in blame-avoiding "no choice" narratives, see H4). From a deservingness viewpoint, by contrast, such encompassing frames should be less effective as they are by definition less clear about groups. Hence, frames that mix many pressures should impact less as it becomes harder to extract deservingness information.

\section{RESEARCH DESIGN, DATA AND METHODS}

We designed three identical survey experiments in Germany, Norway and Sweden, carried out in 2014-15. The German experiment was embedded in an online survey of 1860 respondents fielded in April 2015 by Yougov. The sample is a quota sample based on census 
data about region, age, gender, education from its pool of volunteers. ${ }^{45}$ The Norwegian experiment was embedded in a survey of 2836 respondents carried out in late March 2014 by TNS Gallup. The sample is drawn from TNS Gallup's pre-recruited panel consisting of 50000 individuals. The Swedish experiment was embedded in the citizen panel of Laboratory of Opinion Research (LORE), University of Gothenburg, and fielded in early spring 2015 and includes 3729 respondents. It uses a non-random quota design as in Germany. ${ }^{46}$ In terms of the internal validity of the experiment, all three samples are equally good. In terms of external validity, the Norwegian data fare better as the sample comes from a group of volunteers who originally were recruited by a random selection from the Norwegian resident population.

\section{Experimental design}

The treatments were randomly assigned at the individual level. In Germany, the random assignment was stratified by region of residence (East/West) with 20 percent of all individuals in a treatment group living in the East. We operationalized five types of pressures: "the ageing population," "the high number of people at an employable age not working," two types of immigration ("EU" and "non-western") ${ }^{47}$, and the "financial crisis." We also developed a frame that combined these pressure types (see Table 1). In addition, as all three countries are relatively affluent welfare states, we designed a frame that highlighted their (relatively) favourable economic situation with positive welfare state implications. This leaves us with

\footnotetext{
${ }^{45}$ YouGov Germany maintains a database of hundreds of thousands self-recruited volunteers. For each survey, a quota sample is drawn that gives preference to respondents who have not completed a survey recently. Within the contstraints of the demographic quotas and the recent survey-taking history, requests to participate are assigned at random.

${ }^{46} \mathrm{We}$ do not have a response rate for Germany and Sweden as the sampling follows the logic of a nuanced quota design without a random component. In a quota sample, respondents in a certain group are recruited until the quota is filled. Non-willing volunteers are not counted towards the quota. For Norway, the response rate was 50.1 per cent.

${ }^{47}$ We used "non-western immigration" in Norway and Sweden, and "non-European" immigration in Germany.
} 
seven treatment groups. ${ }^{48}$ These are compared to a control group which did, like everyone else, receive an opening sentence telling them there is "some debate" about welfare state costs. This is in itself a weak reminder about reform pressures. The control group, however, did then not receive any additional information telling them what it is specifically that pressures the welfare state or why "many people" think so. Since all respondents learned there is some debate about pressures the experiment becomes a conservative but well-controlled test capturing largely the impact of receiving additional information about specific pressure in various combinations. Specifically, the experiment was embedded in the following question: ${ }^{49}$

"There is some debate about (insert A Table 1) the costs associated with social security systems and public services in [country]. (Insert B Table 1). Thinking ahead 10 years from now, for each of the following social security and public services, where would you place yourself on a scale from 1-7, where 1 means that [country] will not be able to afford the present level of social security and public services, and 7 means that [country] will be able to afford to increase the level?"

Table 1 Treatment (insertions) and experimental groups:

- EXPERIMENT GROUP 1: "THE GRAY WAVE"

$\circ \quad A=$ how an increasingly aging population affects

- $\mathrm{B}=$ Many people believe that this "gray wave" generates costs that eventually will make it difficult to maintain the current levels of social security and public services.

- EXPERIMENT GROUP 2: "TOO FEW PEOPLE WORKING"

- $\mathrm{A}=$ how the high number of people at an employable age who are not working in [country] affects

- $\mathrm{B}=$ Many believe that the high proportion of people on various social benefits generates costs that will eventually make it difficult to maintain the current levels of social security and public services.

- EXPERIMENT GROUP 3: "HIGH LEVEL OF IMMIGRATION FROM THE EU/EEA"

$\circ \mathrm{A}=$ how immigration from the EU/EEA area affects

○ $\quad \mathrm{B}=$ Many people believe that labour migration from the EU / EEA area generates costs that will eventually make it difficult to maintain the current levels of social security and public services.

- EXPERIMENT GROUP 4: "HIGH LEVEL OF NON-WESTERN IMMIGRATION"

$\circ \quad \mathrm{A}=$ how non-western immigration affects

○ $\quad \mathrm{B}=$ Many people believe that non-western immigration generates costs that will eventually make it difficult to maintain the current levels of social security and public services.

- EXPERIMENT GROUP 5: "ECONOMIC CRISIS IN EUROPE AND THE WORLD"

$\circ \mathrm{A}=$ how the deep and prolonged economic crisis in the world and Europe affects

\footnotetext{
${ }^{48}$ The assignment was random with regard to gender, education, and age (see Table B.1).

49 The question is an adapted version of an item included in the 2008 wave of the European Social Survey.
} 
○ $\quad$ =Many people believe that the economic crisis will also affect [country]'s economy and generate costs that will eventually make it difficult to maintain the current levels of social security and public services.

- EXPERIMENT GROUP 6: "FAVORABLE SITUATION" (6A shall not contain the last part of the sentence that is formulated above, only the part that comes before the addition)

- A = how [country]'s favourable economic situation affects the country's opportunities with regard to social security systems and public services

○ $\quad b=$ Many people believe that this favourable economic situation will eventually make it possible to maintain or increase the current levels of social security and public services

- EXPERIMENT GROUP 7: "ALL REFORM PRESSURES AT ONCE"

○ $\mathrm{A}=$ Is blank

- $B=[$ country $]$ faces a number of challenges that may contribute to increasing these costs and reducing revenues. These challenges include an aging population, and the fact that a large and growing proportion of people at an employable age are not working. In addition, different types of immigration increase, and the world economic crisis affects the [country's] economy. Many people believe that these challenges generate costs that will eventually make it difficult to maintain the current levels of social security and public services.

\section{Dependent variable}

The dependent variable comes from a subsequent battery on sustainability in seven policy areas: public health care, old age pensions, sickness benefits, unemployment benefits, social welfare benefits, elder care, and child care. These items are combined in an additive "sustainability index," comprising all these items. Principal component analysis shows that all items load strongly on one underlying factor. Cronbach's Alpha for the index is .96, being almost the same across all countries. ${ }^{50}$

\section{RESULTS}

Table 2 gives an impression of the seven sustainability items and the index. As might be expected, Norwegians clearly worry the least about welfare state sustainability. By contrast, Germans are the most worried with Swedes falling exactly in between. The order of countries is the same across policy areas.

\footnotetext{
${ }^{50}$ The items varied by the proportion by which respondents indicated "don't know". The likelihood of giving an answer other than "don't know" is unrelated to the revealed attitude. "Don't know" respondents were recoded to the central category of 4 (see Appendix $\mathrm{C}$ for further details).
} 
Table 2 Means for all respondents on the seven sustainability items, and the sustainability index

\begin{tabular}{l|cccccccc|c}
\hline & $\begin{array}{c}\text { Sustainab } \\
\text { ility } \\
\text { index }\end{array}$ & Health & Pensions & Sick pay & Unempl & $\begin{array}{c}\text { Social } \\
\text { benefits }\end{array}$ & $\begin{array}{c}\text { Elder } \\
\text { care }\end{array}$ & $\begin{array}{c}\text { Child } \\
\text { care }\end{array}$ & N \\
\hline Norway & 30.1 & 4.7 & 4.3 & 4.1 & 4.0 & 4.0 & 4.5 & 4.6 & 2754 \\
Sweden & 27.2 & 4.2 & 3.6 & 3.8 & 3.8 & 3.7 & 3.9 & 4.2 & 3207 \\
Germany & 24.3 & 3.5 & 3.1 & 3.6 & 3.5 & 3.4 & 3.3 & 3.8 & 1859 \\
\hline
\end{tabular}

Q: Thinking ahead 10 years from now, for each of the following social security and public services, where would you place yourself on a scale from 1-7, where 1 means that [country] will not be able to afford the present level of social security and public services, and 7 means that [country] will be able to afford to increase the level?". Explicit "don't know" answers recoded to the neutral category. Only for respondents who answered all items.

We now proceed in two steps to test the six hypotheses. We first investigate the main effects of reform pressure framing, comparing these across stimuli, thus testing $\mathrm{H} 1, \mathrm{H} 4$, and $\mathrm{H} 5$. We analyse the experimental effects by a simple OLS regression model with dummies for countries. ${ }^{51}$ In a second step we examine moderation effects arising from both general welfare state support $(\mathrm{H} 2)$ and support for government responsibility in specific policy areas that are associated with a given frame (H3).

\section{Main experimental effects}

Table 3 reports two series of regressions. ${ }^{52}$ One shows the impact of receiving any kind of information about a negative pressure, alongside that of the one positive frame. On average, receiving any of the negative frames reduced belief in sustainability by about .83 scale points compared to the control group $(\mathrm{p}=.03) .{ }^{53}$ This effect across the three countries is about seven

\footnotetext{
${ }^{51} \mathrm{We}$ report $\mathrm{R}^{2}$ values, but as the purpose is to estimate the causal impact of the frames and not a full model to explain the variance of the dependent variable, a high $\mathrm{R}^{2}$ is not the main goal.

${ }^{52}$ For the analysis that includes data from all three country surveys, we weigh the data so that each country-time context is equally relevant for the estimates.

${ }^{53}$ Most of our hypotheses are directional, implying that a one-sided significance test would be appropriate.

However, the multiple comparisons of different treatment groups in a one-short experiment requires the adaption
} 
percent of the standard deviation. Interestingly, there is no corresponding positive effect of the largely positive storyline that the welfare state is in good shape despite some talk about costs. Breaking down these results by country yields a further observation: effects are only significant in the two Scandinavian countries; indeed, the p-value of an F-test comparing models with and without experimental variables is highly insignificant at .76 in Germany. So overall, hearing about these pressures does so little in Germany that the variation may be due to chance alone.

Models 5-8 further unpack the negative frames. Already the pooled model 5 suggests considerable variation. The strongest effects, relative to the control group, come from the two immigration-related stimuli. Individuals informed about EU migration pressure are on average about 1.36 scale points lower on the sustainability index compared to the control group $(\mathrm{p}=.005)$. Pressure emanating from non-Western (Scandinavian formulation)/non-European (German formulation) has a somewhat stronger estimate effect of about $-1.86(\mathrm{p}=.000)$. This corresponds to about 16 percent on the standard deviation. The third biggest effect stems from the "all pressures" treatment containing all the negative pressures used elsewhere $(b=-.85$; $\mathrm{p}=0.08$ ). All other treatments have non-significant effects with population ageing performing the worst, and "too few working" only approaching significance in the pooled analysis ( $b=-.72 ; p=.14)$. Consistent with $\mathrm{H} 5$, then, the uncovered hierarchy of effects reflects what we know about Europe's deservingness culture. ${ }^{54}$ Effects indeed appear to depend on whether

\footnotetext{
of significance levels to multiple testing. Since the number of comparisons differs by our models, the calculation of the appropriate levels by means of the very conservative Bonferroni method is lengthy. Also, there is considerable disagreement in the literature as to the appropriate methods of adjustment (Shaffer 1995). We thus decided to report the unadjusted p-values of the two-sided tests as a kind of middle ground between the two approaches of multiple testing and one-sided tests of directional hypotheses.

${ }^{54}$ van Oorschot 2006.
} 
information about reform pressure "zooms in" on specific costs associated with a particular group, and how (un)deserving that group is regarded to be.

It is interesting that the encompassing pressure frames matter less than the immigration frames. Specifically, the international crisis message is wholly inconsequential while the "all pressures at once" effect is just under half and two-thirds respectively of the immigration estimates. These observations are not very consistent with $\mathrm{H} 4$, which expects multiple and encompassing reform pressure framing to be especially effective. Note also that the immigration information is part of the "all pressures" information. Thus, only hearing about immigration produces stronger effects than hearing about immigration as well as ageing, low employment, and a financial crisis. These observations fit well with deservingness theory in that citizens react more to information that singles out supposedly undeserving groups. They are less consistent with the blame avoidance-inspired notion that citizens are especially sensitive to ubiquitous and overwhelming pressure. 
Table 3 OLS Regression Models of the Perceived Welfare State Sustainability Index ( $b$ coefficients with $p$ values in brackets).

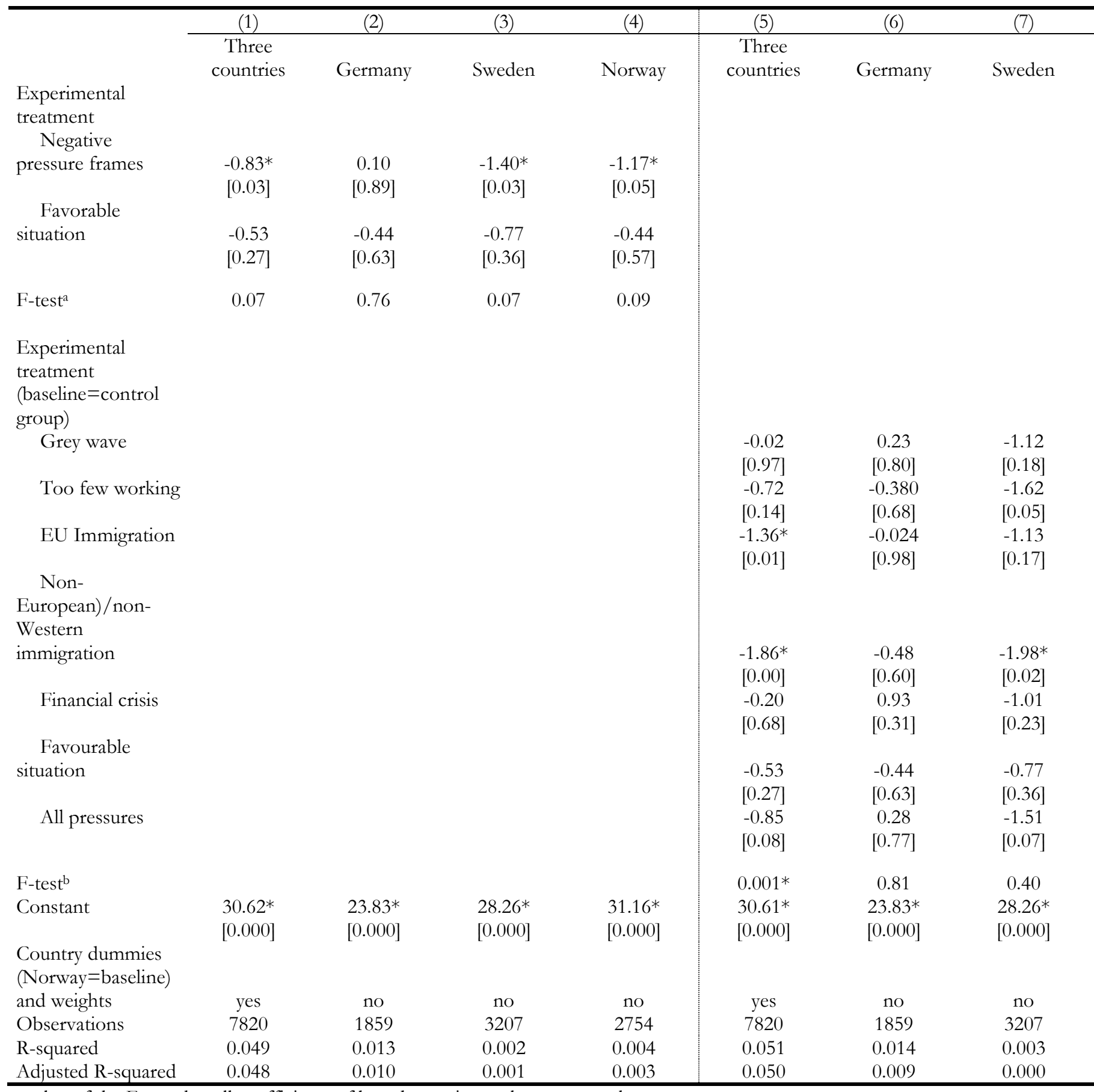

${ }^{a} \mathrm{p}$-value of the F-test that all coefficients of broad experimental groups equal to zero

${ }^{b}$-v-value of the F-test that all coefficients of single experimental groups equal to zero

Note: All regressions include a control for whether the value of the dependent variable has been imputed (see methods section). Models with German data include a control variable for region of residence (West, East) to account for residual regime socialization effects (see Goerres and Tepe 2012). Additional models with extra control variables for gender, income, age and education do not differ much in the estimated experimental effects. Models that are fitted separately for East and West Germany do not yield statistically significant differences. 
At the same time, the "all pressures" frame is not wholly inconsequential. Thus, while H4 is not strongly supported it is also the case that encompassing pressure framing adds something over and above deservingness. Apparently reform pressure framing can play some role even though it is confusing about deservingness (i.e. mixing pressures linked to deserving and undeserving groups, and with pressures unconnected to groups), at the same time as it is clear and dramatic on the multiple sources of rising welfare state costs. ${ }^{55}$

Breaking down results by country (models 6 to 8) again reveals no effects in Germany, stronger effects with significant coefficients in Sweden, and the strongest single effects in Norway. ${ }^{56}$ The non-Western immigrant treatment has a significant impact in both Scandinavian countries, but is more influential in Norway $(b=-3.11 ; p=.000$, whereas $b=-1.98$; $\mathrm{p}=0.02$ in Sweden;). Only in Norway, moreover, does the EU immigration treatment matter $(b=3.0 ; p=.000)$. Further, the estimates for "all pressures" in the two Scandinavian countries are -1.51 and -1.34 respectively with p-values around .07. Finally, only in Sweden do we see an effect of the "too few working" frame $(-1.62 ; \mathrm{p}=.05)$. Overall, we can say that Swedish effects are slightly stronger but also more dispersed across frames. By contrast, Norwegians react most strongly to immigration with the non-Western frame causing a decline in the belief in long-term sustainability of about 30 percent of the standard deviation.

To summarize, we have unearthed considerable heterogeneity and limitations in reform pressure framing effects, both across frames and contexts. Contrary to H1, there is

\footnotetext{
55 The influential work of Zaller (1992) suggests that political awareness often interacts with information processing. However, we find no interaction effects between reform pressure framing and political awareness (operationalized using an additive index based on political interest (0-3), political discussions (0-3), and political news consumption (0-3)).

${ }^{56}$ Indeed, Norway is the only country where the F-Test has a clearly significant p-value, meaning that only in Norway the statistical model is clearly improved by the experimental set-up.
} 
little in the way of generally present effects. Instead, H5 receives a good amount of support in that deservingness cues matter. Also, and somewhat consistent with $\mathrm{H} 4$, a frame that "zooms out" and encompasses many pressures at once (but is unclear on deservingness) made some impression in 2 of 3 countries.

Finally, it is clear that the results suggest variation not just across frames. There also seems to be interactions between country context and specific stimuli. The obvious example is the strong immigration effects in Norway, but one can mention the importance of low employment in Sweden. Interestingly, this last observation about Sweden is underscored by further analyses of specific components of the sustainability index (not shown, see Table E.1). While in general the experimental treatments have relatively similar effects on all components of the sustainability index, items related to the labor market behave differently in Sweden. To begin with the "too few working" treatment affects sustainability perceptions in most policy areas in Sweden, but effects are above average in two areas most directly linked to this pressure: unemployment benefits and sick pay. In Sweden, moreover, sick pay perceptions are affected by reform pressure framing of all kinds. Said differently, all conditions impact significantly on Swedes' sustainability perceptions in this particular policy area. The concluding section will discuss possible explanations and avenues for further research on these discoveries about country-policy area interactions.

\section{Moderated effects?}

$\mathrm{H} 2$ and $\mathrm{H} 3$ predict that people with high levels of welfare state support are less affected. However, we find no support for $\mathrm{H} 2$ stating that general welfare state support hinders pressure framing. We ran a series of regressions involving interactions between seven treatments and general welfare state support, on the seven policy items and the sustainability 
index, in two countries. ${ }^{57} \mathrm{We}$ found no significant interactions. ${ }^{58}$ Further, H3 states that those with stronger support for a specific related policy area are less affected by an associated reform pressure. Here, we ran four regressions for Germany and Norway respectively to check whether support for government responsibility conditions the effects (detailed results in Table F.1). As moderators, we used well-known items on "government responsibility" for providing a reasonable standard of living for the old, for the unemployed, and for migrants ( 0 to 10 , with higher values indicating more support). ${ }^{59}$ Specifically, three items are relevant for four corresponding frames: ensure a reasonable standard of living for the unemployed ("too few working"); ensure a reasonable standard of living for the old ("grey wave"); ensure a reasonable standard of living for immigrants (the two immigration treatments).

We find only sporadic support for H3. As seen in Table F.1 (Appendix), F-tests comparing models with and without "treatment X specific support" interactions suggest no model fit improvement for the population ageing and low employment treatments. However, for the strongest effects in our analysis - i.e. those of immigration — we find interactions with support for government responsibility in this area. This provides a modicum of support for H3 in the area where pressure framing matters the most.

Figure 1 illustrates marginal effects of the two immigration frames, relative to the control group, in Germany and Norway. The x axis represents the moderator variable, i.e. support for the government providing a reasonable standard of living for immigrants.

\footnotetext{
${ }^{57}$ The moderating variables were only included in the German and Norwegian surveys.

58 Detailed results available upon request.

${ }^{59}$ The moderator items were placed after the treatments with varying amounts of survey time between them, but the levels of the moderators were not influenced by the experimental treatment.
} 
Figure 1: Predicted marginal effects of the immigration frames across levels of support for government responsibility for providing reasonable standard of living for immigrants.
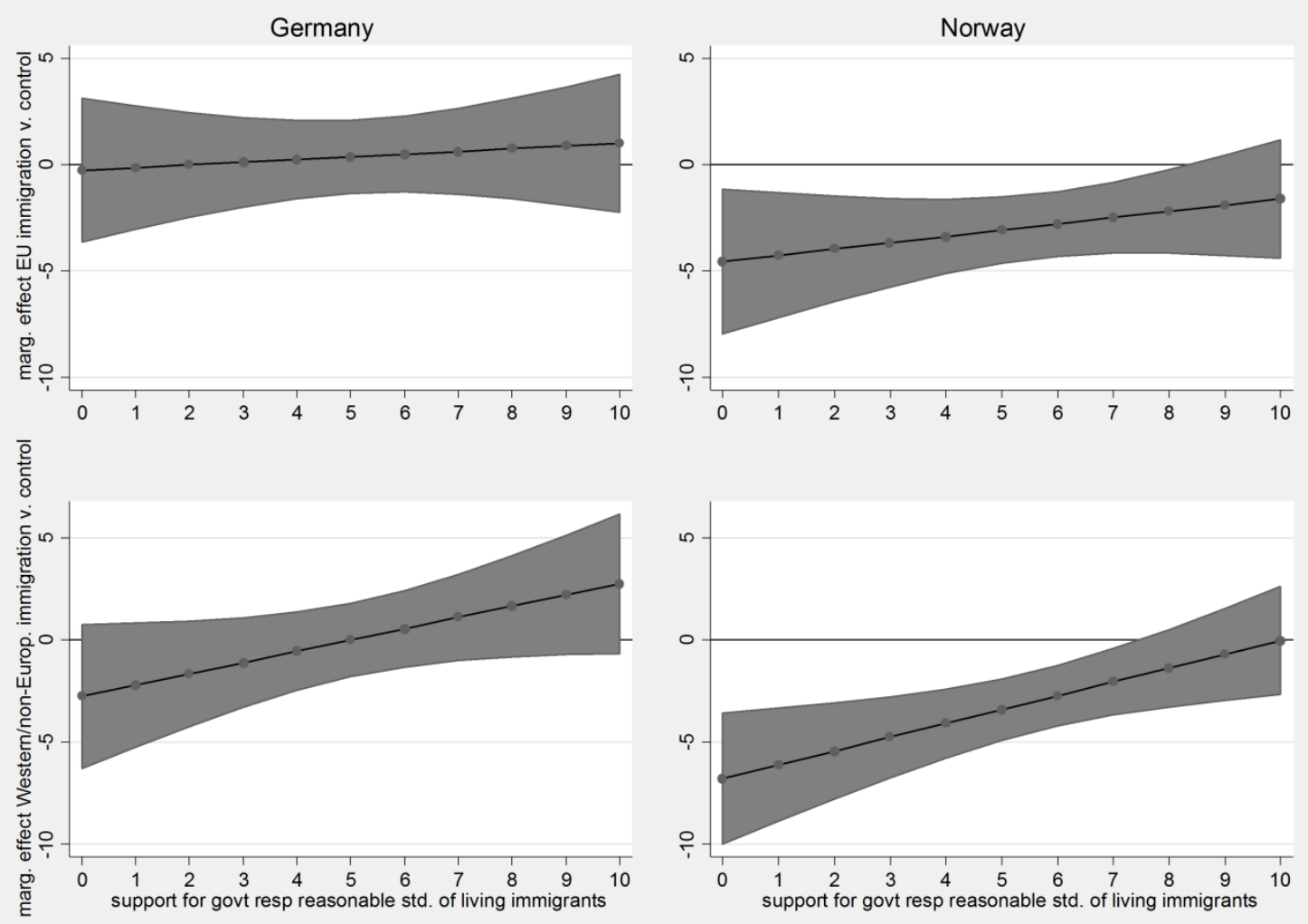

Note: The graphs show the point estimates of the marginal effect of the immigration frames compared to the control group at all 11 values of the contextual variables (government should provide a reasonable standard of living for immigrants). The band stands for the $95 \%$ confidence interval.

The EU immigration frame is not significantly moderated here as illustrated by a rather flat gradient in the first row both for Germany and Norway. When individuals are confronted with the non-Western immigration frame, however, their reaction is clearly contingent. In Norway, those at scale values 8 to 10 (about one-third of the sample) are not estimated to be significantly affected by the non-Western frame compared to the control group. Those who indicate a value of 0 to 7, however, react significantly. In Germany, we see a similar pattern, although the effect estimates are actually positive for values of the moderator variable of 6 and higher (about 45 percent of the sample). Only for those with very low support for government responsibility for immigrants is the estimated negative effect close to being significant at the .05 level. 


\section{CONCLUSION: ONE OR TWO PATHS TO EFFECTIVE PRESSURE FRAMING?}

We conducted an experiment in three countries testing whether exposure to welfare state "reform pressure" frames triggers concern about the long-term financial sustainability of the welfare state. We formulated hypotheses in communication with three bodies of research. As explained below, all three have implications that receive some support, at the same time as none of them provides the full story of the empirical results.

Perhaps the best way to summarize is to say that pressure framing has a clear causal potential that is not always realized. In fact, exposure to several major cost-inducing welfare state challenges — most notably population aging — did not make people more worried about sustainability against much expectation in the literature on the politics of aging where that objective pressure is assumed to be dominant in citizens' heads (see Goerres and Vanhuysse 2012). This observation, together with the fact that most significant coefficients are generally moderately sized, fits the "new politics" depiction of welfare states and citizens as changeresistant despite heavy reform pressure. Other observations, however, are less consistent with implications we teased out of the "new politics" framework. By example, we found that whenever framing matters it usually does so across broad attitudinal groups. Here, the migration frames worked differently with clearer interactions with immigration support. But overall, and mostly inconsistent with $\mathrm{H} 2 / 3$, successful pressure framers may not risk indifference, and certainly not backlash, among groups strongly predisposed against their message. Thus, whatever obstacles exist for pressure framing, strong welfare state support may for the most part not be one of them. Also interesting in this regard is that we found no positive effects of a positive message saying the welfare state is in good shape. So even though "pressure framers" may struggle to sway the public they may not need to worry about "pressure deniers" (as could be expected on the assumption that people are biased towards the status quo). 
Some treatments, furthermore, indeed yielded substantively important effects. Before getting into details, this generally fits recent work on welfare state change. Here, some scholars observe that welfare reforms have come with open "credit claiming" by leaders. Others report that citizens have economic perceptions of the welfare state that are partly orthogonal to normative support, showing how perceptions moderate electoral punishment for potentially unpopular reform. We add evidence suggesting that citizens are at least in principle perfectly able to draw key conclusions about welfare sustainability from brief reminders about reform pressures. This is consistent with the view that successful pressure framing is part of the explanation for why significant reforms have not triggered electoral punishment despite strong support for status quo. Of course, our experimental data cannot determine whether this inference to real-world politics is valid. But overall, evidence is mounting that "new politics"-inspired blame avoidance does not provide the full story behind accelerating welfare state change.

Crucially however, effects vary greatly across the negative pressure frames. Consistent with "deservingness theory" they elicit stronger effects if pressure is linked to groups generally seen as undeserving. Linking immigration and, to a lesser extent, low employment rates with costs appear to boost effects compared to population ageing which elicits no impact. This hierarchy of effects indeed suggests deservingness theory is key to understanding also economic messages about the future of the welfare state. Specifically, it suggests deservingness theory is useful for specifying the "normative" arguments emphasized in work on "credit claiming," "ideational leadership," and similar phenomena that have been argued to drive welfare state change.

There may, however, to be another path to effective pressure framing. Consistent with ideas taken from the "new politics" framework," we found some impact of a broader stimulus that was dramatic and clear about reform pressure, but confusing about deservingness. 
Although its effect was clearly weaker compared to immigration frames, this "all pressures" treatment did play some role in two of three countries.

Overall, these results suggest that reform-minded politicians who want to take their case to the public are left with a choice. Either they zoom in on pressures linked to undeserving groups, or they zoom out, making messages span a broader mix of multiple challenges. The choice is not entirely easy. Especially when it comes to stressing immigration, there are obvious ideological and political obstacles for most party families. In some countries, only populist right parties are comfortable with it. Immigration treatments were also the most divisive ones in our experiments. While interactions with attitudes were generally absent, antipathy towards immigrants did inflate the impact of hearing that immigrants pressure our welfare state.

Politicians who do not want to play the immigration card, or are else unable to formulate a deservingness-based narrative, can still zoom out and formulate encompassing messages about multiple economic pressures. This may be palatable for more party families in most democracies. However, judging from our results, this message is likely to make a weaker, if any, imprint. Future research is clearly needed here, however. One issue has to do with the precise contents of our "all pressures" frame. We only tested one of the many possible permutations of the message that the welfare state is under multiple pressure. Perhaps citizens are more susceptible to particular combinations of, and narratives about, broad reform pressure? Another limitation has to do with experimental design. Our experiment made progress by combining economic pressures and deservingness in one design, using differences across types of economic pressures to get at deservingness variation. But one can certainly imagine more factorial designs that independently vary these and other relevant aspects, including pressure type, pressure severity, and implied deservingness of related groups, such that the different possible combinations can be disentangled. 


\section{OUTLOOK: TWO LESSONS ABOUT COUNTRY VARIATION}

We found clear country differences in pressure framing effects. This section identifies two possible explanations that may be examined in future research. They grow directly out of the empirics but it must be said that they were mostly not theoretically anticipated. We treat them as inductive products of our undertaking and emphasize that they require future deductive testing.

One lesson concerns the importance of immigration. Our data indicate that especially Norwegian, but also Swedish respondents, are more prone than German ones to react to immigration as a cost-inducing reform pressure. This is consistent with several single-country studies showing that exposure to various immigration-related stimuli affects welfare staterelated attitudes in Scandinavia. ${ }^{60}$ But what is more, our results fit with a recent two-country experimental comparison in which Fietkau and Hansen (2017:17) found that "Danes react more strongly to immigrants' educational and qualification background than do Germans. We argue that because of Denmark's larger welfare state and significantly larger social benefit spending, Danes are more afraid that immigration will pose a threat to their universal welfare system. Danes may perceive immigrants as exploiting welfare benefits more than natives and thus as bearing a high economic cost." In sum, then, current evidence is consistent with an institutional explanation of country variation: citizens in larger and more universal welfare states, whose services and benefits are more generous (and possibly easier to access) are more sensitive to the notion that immigration constitutes an economic reason to worry about welfare state sustainability. ${ }^{61}$

At the same time, our three-country study of multiple reform pressures uncovered a more complex contextual pattern indicative of a second lesson. It seems that effects grow

\footnotetext{
${ }^{60}$ e.g. Aalberg et al. 2012; Bay et al. 2016; Hjorth 2016; Cappelen and Midtbø 2016.

${ }^{61}$ See also Naumann and Stoetzer 2018 for a recent experimental study reporting stronger effects in Norway than in Germany and The Netherlands.
} 
where reform pressures have been recently and massively debated in the public sphere. This "salience explanation" is consistent with standard assumptions in political psychology where recently activated "cognitive schemas" are more likely to be applied again than those rarely used. Zaller drew on this idea in his "accessibility axiom," stating that "the more recently a consideration has been called to mind or thought about, the less time it takes to retrieve that consideration or related considerations from memory and bring them to the top of the head for use." ${ }^{2}$ Similarly, scholars working specifically on framing often assume, or find, that people "embrace the frame they hear most often and that most easily comes to mind."

One can see the relevance of salience when juxtaposing key results with recent developments in each country. Beginning with Norway, we find that the strongest effects in our data concern both kinds of immigration. This is logical from a salience perspective, given that the populist right had in 2014 recently entered the government, and given that an influential government task force had for several years forcefully drawn the attention of policy-making elites, and the wider public, to the welfare-immigration nexus. ${ }^{64}$ Importantly, this debate concerned immigration from the EU/EEA as much as it concerned refugee immigration from outside Europe.

Looking to Sweden, the 2006-2014 centre-right government's main winning narrative was arbetslinjen. The idea was that employment levels were too low to sustain the welfare state and the economy, and that incentive-oriented tax reforms, activation, tightened conditionality, and some retrenchment was needed. Employment issues were highly salient among voters in the 2006 and 2010 elections. The centre-right coalition took over issue

\footnotetext{
${ }^{62}$ Zaller 1992, 48.

${ }^{63}$ Chong and Druckman 2007, 104.

${ }^{64}$ NOU 2011:7. Brochman and Grødem 2013.
} 
ownership in this area. ${ }^{65}$ Because "arbetslinjen" dominated Swedish politics for several years, and because some of the most controversial reforms involved sick pay and unemployment benefits, it is logical that pressure framing effects in Sweden arise for both treatments and dependent variables related to these topics.

The non-western immigration frame (but not EU immigration) also matters in Sweden. From a salience perspective this makes sense. In the summer of 2014, the conservative Prime Minister Fredrik Reinfeldt held a massively debated speech, and a press conference, to kick off the election campaign. He forcefully put the increase in refugees after the Syria crisis on the campaign agenda. Although he famously asked his fellow citizens to "open their hearts," he also used the occasion to be frank about budgetary implications, arguing there could now be no expansive election promises. In the subsequent election, the populist radical right Sweden Democrats received an eye-popping 13 percent while the prime minister was widely interpreted as, and often blamed for, pitting immigration against the welfare state and making this a defining campaign feature. Overall, it makes sense that some six months later we find that Swedes are sensitive to pressure framing concerning especially non-western immigration. The German data threw up little impact and hence fewer clues. At the same time, the largely absent effects in Germany could be explained by declining overall attention to welfare sustainability in recent years. This drop might in turn have happened partly because major reforms addressing reform pressure were implemented in an earlier phase. Of course, Germany's Bismarckian social insurance systems, with their emphasis on status maintenance principles, were long seen as impervious to reform. This perception, however, has changed, with public agenda attention at its peak during the Reformstau debate of the late 1990s and early 2000s. ${ }^{66}$ This debate eventually produced reforms of pensions, unemployment benefits,

\footnotetext{
${ }^{65}$ Oscarsson and Holmberg 2013.

${ }^{66}$ Palier 2010.
} 
and family policy. After that, Zohlnhöfer notes, debates about pressures and reforms declined markedly with subsequent governments being "unwilling to pursue further some of the reform projects they themselves had embraced [...] and talk about a 'German employment miracle' began $[\ldots]$ This meant that reforms appeared less urgent for the time being, while it would have become particularly difficult to communicate the reforms as necessary and appropriate to the voters."

The salience perspective has an important implication: reform pressure framers can "pave the way for their own success." That is, if pressure frames accumulate in a somewhat concentrated period they contribute to an overall context in which further opinion formation on the same topic works smoother. A momentum may be created in which pressure awareness builds at the same time as the conditions for future framing effects of the same kind improve. Of course, such a momentum is unlikely to last forever. Eventually even the most salient issues will wane, in part due to ever-changing issue attention cycles, ${ }^{68}$ or by more sudden and dramatic "punctuated equilibria." ${ }^{69}$ Moreover, agenda shifts may be especially likely whenever politicians change actual policy in the process. ${ }^{70}$ In such cases, "thermostatic" reactions to actual reforms may quickly take citizens' back to a more skeptical stance, ${ }^{71}$ thus contributing further to a closing of the reform window that pressure framing initially helped open.

\footnotetext{
${ }^{67}$ Zohlnhöfer 2015, 13-14.

${ }^{68}$ Downs 1972.

${ }^{69}$ Baumgartner et al. 2009.

${ }^{70}$ Soss and Schram 2007.

${ }^{71}$ Soroka and Wlezien 2010; Naumann 2014.
} 


\section{REFERENCES}

Aalberg, Toril, Shanto Iyengar and Solomon Messing. 2012. Who is a 'Deserving' Immigrant? An Experimental Study of Norwegian Attitudes. Scandinavian Political Studies 35(2):97-116.

Armingeon, Klaus, and Nathalie Giger. 2008. Conditional Punishment: A Comparative Analysis of the Electoral Consequences of Welfare State Retrenchment in OECD Nations, 19802003. West European Politics 31(3):558-80.

Arndt, Christoph. 2014. The Electoral Consequences of Reforming a Bismarckian Welfare State. Pp. 132-55 in How Welfare States Shape the Democratic Public: Policy Feedback, Participation, Voting, and Attitudes, edited by Staffan Kumlin and Isabelle Stadelmann-Steffen. Cheltenham, UK: Edward Elgar Publishing.

Baumgartner, Frank R., Christian Breunig, Christoffer Green-Pedersen, Bryan D. Jones, Peter B. Mortensen, Michiel Nuytemans, and Stefaan Walgrave. 2009. Punctuated Equilibrium in Comparative Perspective. American Journal of Political Science 53(3):603-20.

Bay, Ann-Helén, Aksel Hatland, Tale Hellevik, and Charlotte Koren (Eds.). 2010. De norske trygdene. Oslo: Gyldendal.

Bay, Ann-Helén, Henning Finseraas and Axel West Pedersen. 2016. Welfare Nationalism and Popular Support for Raising the Child Allowance : Evidence from a Norwegian Survey Experiment. Scandinavian Political Studies 39(4):482-494.

Bay, Ann-Helén and Axel West Pedersen. 2006. The Limits of Social Solidarity: Basic Income, Immigration and the Legitimacy of the Universal Welfare State. Acta Sociologica, 49(4), 419-436.

Beramendi, Pablo, Silja Häusermann, Herbert Kitschelt, and Hanspeter Kriesi (Eds.). 2015. The Politics of Advanced Capitalism. Cambridge: Cambridge UP.

Bonoli, Guiliano. 2005. The Politics of New Social Policies: Providing Coverage against New Social Risks in Mature Welfare States. Policy and Politics 33(3):431-49.

-. 2012. Blame Avoidance and Credit Claiming Revisited. Pp. 93-110 in The Politics of the New Welfare State, edited by Guiliano Bonoli and David Natali. Oxford: Oxford University Press.

Brochmann, Grete; Anne Skevik Grødem. 2013. Migration and welfare sustainability. The case of Norway. In Grete Brochman and Elena Jurado (eds.) Europe's immigration challenge. Reconciling work, welfare and mobility. London: I.B. Tauris.

Brooks, Clem. 2011. Framing Theory, Welfare Attitudes, and the United States Case. Pp. 193-221 in Constested Welfare States: Welfare Attitudes in Europe and Beyond, edited by Stefan Svallfors. Stanford: Stanford UP.

Cappelen, Cornelius, and Tor Midtbø. 2016. "Intra-EU Labour Migration and Support for the Norwegian Welfare State." European Sociological Review 32(6):691-703.

Chong, Dennis and James N. Druckman 2007. Framing Theory. Annual Reviw of Political Science. 10:103-26.

Cox, Robert Henry. 2001. The Social Construction of an Imperative: Why Welfare Reform Happened in Denmark and the Netherlands but Not in Germany. World Politics 53:46398.

Downs, Anthony. 1972. Up and Down with Ecology: The Issue-Attention Cycle. Public Interest 28:38-46.

Druckman, James N, Donald P. Green, James H. Kuklinski, and Arthur Lupia (Eds.). 2011. Handbook of Experimental Political Science. Cambridge: Cambridge University Press.

Elmelund-Præstekær, Christian, and Patrick Emmenegger. 2013. Strategic Re-framing as a Vote Winner: Why Vote-seeking Governments Pursue Unpopular Reforms. Scandinavian Political Studies 36(1):23-42.

Entman, Robert M. 1993. Framing: Toward Clarification of a Fractured Paradigm. Journal of Communication. 43(4):51-58. 
Esmark, Anders and Sarah R. Schoop. 2017. Deserving social benefits? Political framing and media framing of 'deservingness' in two welfare reforms in Denmark. Journal of European Social Policy. 27(5):417-432.

Ferrera, Maurizio. 2008. The European Welfare State: Golden Achievements, Silver Prospects. West European Politics 31(1-2):82 - 107.

Fietkau, Sebastian and Kasper M. Hansen. 2017. How perceptions of immigrants trigger feelings of economic and cultural threats in two welfare states. European Union Politics. Published online before print.

Giger, Nathalie. 2011. The Risk of Social Policy: The Electoral Consequences of Welfare State Retrenchment and Social Policy Performance in OECD Countries. London: Routledge.

Giger, Nathalie and Noira Nelson. 2013. The welfare state or the economy? Preferences, constituencies, and strategies for retrenchment. European Sociological Review 29 (5), 1083 1094.

Goerres, Achim and Markus Tepe (2012). Doing it for the Kids? The Determinants of Attitudes towards Public Childcare in Unified Germany. Journal of Social Policy, 41 (2), 349-72.

Goerres, Achim, and Pieter Vanhuysse (2012). Mapping the Field: Comparative Generational Politics and Policies in Ageing Democracies, pp. 1-22 In Ageing Populations in Post-Industrial Democracies: Comparative Studies of Politics and Policies, edited by Pieter Vanhuysse and Achim Goerres. London: Routledge.

Hemerijck, Anton. 2013. Changing Welfare States. Oxford: Oxford University Press.

Hjorth, Frederik. (2016). Who benefits? Welfare chauvinism and national stereotypes. European Union Politics 17(1): 3-24.

Hood, Christopher. 2007. What Happens When Transparancey Meets Blame Avoidance. Public Management Review 9(2):191-210.

Jacobs, Alan. 2016. Policy Making for the Long Term in Advanced Democracies. Annual Review of Political Science 19:433-54.

Jakobsson, Niklas, and Staffan Kumlin. 2017. "Election Campaigns, Government Partisanship, and the Welfare State." European Political Science Review 9(2):183-208.

Jensen, Carsten, and Elias Naumann. 2016. "Increasing Pressures and Support for Public Healthcare in Europe." Health Policy 120:698-705.

Jerit, Jennifer, and Jason Barabas. 2006. Bankrupt Rhetoric: How Misleading Information Affects Knowledge about Social Security. Public Opinion Quarterly 70(3):278-303.

Kangas, Olli E., Mikko Niemelä, and Sampo Varjonen. 2013. When and Why do Ideas Matter? The Influence of Framing on Opinion Formation and Policy Change. European Political Science Review (1-20).

Korpi, Walter, and Joakim Palme. 2003. New Politics and Class Politics in the Context of Austerity and Globalization: Welfare State Regress in 18 Countries, 1975-95. American Political Science Review 97:425-46.

Kuipers, Sanneke. 2006. The Crisis Imperative: Crisis Rhetoric and Welfare State Reform in Belgium and the Netherlands in the Early 1990s. Amsterdam: Amsterdam university Press.

Kumlin, Staffan. 2007. Overloaded or Undermined? European Welfare States in the Face of Performance Dissatisfaction. Pp. 80-116 in The Political Sociology of the Welfare State: Institutions, Social Cleavages, and Orientations, edited by Stefan Svallfors. Stanford: Stanford University Press.

Levi, Margaret. 1997. Consent, Dissent, and Patriotism. New York: Cambridge University Press. Levy, Jonah D. 2010. Welfare Retrenchment. Pp. 552-69 in The Oxford Handbook of the Welfare State, edited by Francis G. Castles, Stephan Leibfried, Jane Lewis, Herbert Obinger, and Christopher Pierson. Oxford: Oxford University Press.

Lewis-Beck, Michael S., and Mary Stegmaier. 2007. Economic Models of Voting. Pp. 518-37 in Oxford Handbook of Political Behavior, edited by Russel J Dalton and Hans-Dieter Klingemann. Oxford: Oxford University Press. 
Lindbom, Anders. 2007. Obfuscating Retrenchment: Swedish Welfare Policy in the 1990s Journal of Public Policy 27(02):129-50

-. 2014. Waking up the Giant: Hospital Closures and Electoral Punishment in Sweden. Pp. 15680 in How Welfare States Shape the Democratic Public: Policy Feedback, Participation, Voting, and Attitudes, edited by Staffan Kumlin and Isabelle Stadelmann-Steffen. Cheltenham, UK: Edward Elgar Publishing.

Mau, Steffen. 2003. The Moral Economy of Welfare States: Britain and Germany Compared. London: Routledge.

Morel, Nathalie, Bruno Palier, and Joakim Palme (Eds.). 2012. Towards a Social Investment Welfare State? Bristol: Policy Press.

Naumann, Elias. 2014. Raising the Retirement Age: Retrenchment, Feedback, and Attitudes. Pp. 223-43 in How Welfare States Shape the Democratic Public: Policy Feedback, Participation, and Attitudes, edited by Staffan Kumlin and Isabelle Stadelmann-Steffen. Cheltenham, UK: Edward Elgar Publishing.

- 2017. Do Increasing Reform Pressures Change Welfare State Attitudes? An experimental study on population ageing, pension reform preferences, political knowledge, and ideology. Ageing and Society 37(2):266-94

Naumann, Elias, and Lukas F. Stoetzer. 2018. "Immigration and Support for Redistribution: Survey Experiments in Three European Countries." West European Politics 41(1):80-101.

NOU. 2011:7. Velferd og migrasjon. Den norske modellens framtid.

Oscarsson, Henrik, and Sören Holmberg. 2013. Nya svenska väljare. Stockholm: Norstedts Juridik.

Palier, Bruno (Ed.). 2010. A Long Goodbye to Bismarck? The Politics of Welfare Reform in Continental Europe. Amsterdam: Amsterdam University Press.

Palier, Bruno, and Claude Martin. 2007. Editorial Introduction: From 'a Frozen Landscape' to Structural Reforms: The Sequential Transformation of Bismarckian Welfare Systems. Social Policy \& Administration 41(6):535-54.

Petersen, Michael Bang, Rune Slothuus, Rune Stubager, and Lise Togeby. 2010. Deservingness versus values in public opinion on welfare: The automaticity of the deservingness heuristic. European Journal of Political Research 50:24-52.

Petersen, Michael, Daniel Sznycer, Leda Cosmides, and John Tooby. 2012. Who Deserves Help? Evolutionary Psychology, Social Emotions, and Public Opinion about Welfare. Political Psychology 33(3):395-418.

Pierson, Paul. 1996. The New Politics of the Welfare State. World Politics 48(2):143-79.

- (Ed.). 2001. The New Politics of the Welfare State. Oxford: Oxford University Press.

Roosma, Femke, John Gelissen, and Wim van Oorschot. 2013. The Multidimensionality of Welfare State Attitudes:: A European Cross-National Study. Social Indicators Research 113:235-55.

Rothstein, Bo. 1998. Just Institutions Matter. The Moral and Political Logic of the Universal Welfare State. Cambridge: Cambridge University Press.

Schmidt, Vivien A. 2002. Does Discourse Matter in the Politics of Welfare State Adjustment? Comparative Political Studies 35(2):168-93.

Scruggs, Lyle. 2008. Social Rights, Welfare Generosity, and Inequality. Pp. 62-90 in Democracy, Inequality, and Representation, edited by Pablo Beramendi and Christopher J. Anderson. New York: Russel Sage Foundation.

Shaffer, Judith P. 1995. Multiple Hypothesis Testing. Annual Review of Psychology 46(1): 561-584.

Slothuus, Rune. 2007. Framing Deservingness to Win Support for Welfare State Retrenchment. Scandinavian Political Studies 30(3):323-44.

Soroka, Stuart N., and Christopher Wlezien. 2010. Degrees of Democracy: Politics, Public Opinion, and Policy. Cambridge: Cambridge UP.

Soss, Joe, and Sanford Schram. 2007. A Public Transformed? Welfare Reform as Policy Feedback. American Political Science Review 101(1):111-27. 
Starke, Peter. 2008. Radical Welfare State Retrechment. Basingstoke: Palgrave-Macmillan.

Stiller, Sabina. 2010. Ideational Leadership in German Welfare State Reform: How Politicians and Policy Ideas Transform Resilient Institutions. Amsterdam: Amsterdam University Press.

Stokes, Donald E. 1963. Spatial Models of Party Competition. American Political Science Review 57:368-77.

Svallfors, Stefan. 2012. Welfare States and Welfare Attitudes. Pp. 1-24 in Contested Welfare States: Welfare Attitudes in Europe and Beyond, edited by Stefan Svallfors. Stanford: Stanford University Press.

Taber Charles S. and Milton Lodge (2006) Motivated skepticism in the evaluation of political beliefs. American Journal of Political Science 50(3): 755-769.

Taylor-Gooby, Peter (Ed.). 2001. Welfare States under Pressure. London: Sage Publications.

Tyler, Tom R., Robert J. Boeckmann, Heather J. Smith, and Yuen J. Huo. 1997. Social Justice in a Diverse Society. Boulder, CO: Westview Press.

van Kersbergen, Kees, Barbara Vis, and Anton Hemerijck. 2014. The Great Recession and Welfare State Reform: Is Retrenchment Really the Only Game Left in Town? Social Policy \& Administration 48(7):883-904.

van Oorschot, Wim. 2000. Who should get What, and Why? On Deservingness Criteria and the Conditionality of Solidarity among the Public. Policy and Politics 28(1):33-48.

-. 2006. Making the Difference in Social Europe: Deservingness Perceptions among Citizens of European Welfare States. Journal of European Social Policy 16(1):23-44.

Van Oorschot, Wim, Femke Roosma, Bart Meuleman, and Tim Reeskens (eds.) 2017. The Social Legitimacy of Social Welfare: Attitudes to Welfare Deservingness. Cheltenham, UK: Edward Elgar Publishing.

Vis, Barbara. 2016. Taking Stock of the Comparative Literature on the Role of Blame Avoidance Strategies in Social Policy Reform. Journal of Comparative Policy Analysis 18:2(2):122-37

Wenzelburger, Georg, and Felix Hörisch. 2016. Framing Effects andComparative Social Policy Reform: Comparing Blame Avoidance Evidence from Two Experiments. Journal of Comparative Policy Analysis 18(2):157-75.

Zaller, John R. 1992. The Nature and Origins of Mass Opinion. Cambridge: Cambridge University Press.

Zohlnhöfer, Reimut. 2015. A Coalition Whose Time Had Already Passed...The Economic and Social Polices of the Second Merkel Government. Pp. 13-30 in Germany after the 2013 Elections: Breaking the Mould of Post-Unification Politics?, edited by Gabriele D'Ottavio and Thomas Saalfeld. Farnham: Ashgate. 